\title{
On Williamson's new Quinean argument against nonclassical logic
}

\author{
Jc Beall \\ entailments.net \\ University of Connecticut
}

Strange phenomena drive a lot of otherwise surprising features of systematic theories, phenomena that buck the usual cases and demand an explanation that goes beyond the obvious norm. This is so not only in philosophy but in all cases of systematic truth-seeking theorizing, from science to theology. For present purposes, let truth-theoretic paradoxes (e.g., liars, etc.) be our paradigm of strange phenomena. In the face of such phenomena many have advanced an account according to which logic is nonclassical. Against such accounts W.V.O. Quine [36] famously argued from a principle of conservatism (viz., minimal mutilation of current theory) and the premise that classical logic is the status quo to the conclusion that, because nonclassical logic appears to reduce (or at least not increase) explanatory power of many true theories (e.g., maths, physics, more), one should reject nonclassical-logic responses to strange phenomena. All of this (and more) is familiar.

Also familiar is that Quine's argument, despite the valuable pragmatist methodology that drives it, is often seen to plainly fail as an argument against nonclassical-logic accounts of strange phenomena. Perhaps the biggest reason for the failure, setting aside his unfortunate charge of 'changing the subject', is that Quine's argument precludes nonclassical logic from the get-go - the central premise claiming both that classical logic is the 'status quo' and that conservatism in our methodology requires us to maintain the status quo (short of some resoundingly loud recalcitrant data that leaves no other option but to dive to the deeper depths of subclassical or otherwise nonclassical logic). In short, Quine's argument simply doesn't touch target nonclassical accounts since it locks them outside from the start.

Can one do better by way of the Quinean argument? Timothy Williamson

Australasian Journal of Logic (16:7) 2019, Article no. 2 
[47] aims to do just that: he presents a new Quinean argument based again on central ingredients of common pragmatism about theory choice (including logical theory, as is common). What makes it new is that, in addition to avoiding Quine's unfortunate charge of mere terminological squabble, Williamson's argument explicitly rejects - at least for purposes of the argument - Quine's key conservatism premise. ${ }^{1}$

In this paper I do two things. First, I argue that Williamson's new Quinean argument implicitly relies on Quine's conservatism principle. Second, by way of answering his charges against nonclassical logic I directly defend a particular subclassical account of logical consequence.

The structure of the paper: $\S 1$ does some (alas, lengthy) stage-setting work (clarifying terminology and background assumptions); $\S 2$ presents the main point that Williamson's new argument fails to bear against the target nonclassical-logic account. $§ 3-\S 4$ briefly illustrate how a subclassical-logic account - our representative nonclassical target of Williamson's argument answers Williamson's objections around 'explanatory loss'.

\section{What is logic?}

The term 'logic' is used for many things. This is uncontroversial. Also uncontroversial (at least these days) is that logic, in a traditionally central sense of the term, is about what follows from what. ${ }^{2}$ Furthermore, and mostly un-

\footnotetext{
${ }^{1}$ Williamson nonetheless endorses the premise that classical logic is the status quo, a premise that I reject if we're clear about which relation we're tagging as 'logical consequence'. I return to this below.

I note that Williamson's argument avoids Quine's unfortunate subject-change charge by explicitly not treating debates over logical consequence as mere verbal disputes or generally metalinguistic. (And on this I fully agree with Williamson over Quine, and so for space reasons say no more of it here - except to flag that Ole Hjortland [25] argues that such debates need to be at least somewhat metalinguistic if our aim is to accommodate a plurality of consequence relations that are beyond those that Williamson discusses. Hjortland's work contributes a new avenue for accommodating non-closure-operator - and slightly metalinguistic - accounts. Because my own interest here, as discussed below, takes the role of logical consequence to be a particular closure relation standardly understood, I set Hjortland's broader account aside here.)

${ }^{2}$ Quine's focus on logical truths, at least as he intended it, assumed a particular deduction theorem. We have the influence of Belnap [14] and Anderson-Belnap [1] for rightly emphasizing that not all theories of logical consequence have a deduction theorem in Quine's assumed sense. (Stephen Read [37] also makes the matter clear, as do Beall
}

Australasian Journal of Logic (16:7) 2019, Article no. 2 
controversial among active philosophers of logic, is that the pragmatists (e.g., Harman, Putnam, Quine and many others) are more or less right, at least in spirit, about the epistemic status of logic: there's nothing epistemically - or, for that matter, metaphysically, politically, theologically - special about the given discipline of logic; there's nothing epistemically (metaphysically, etc.) 'exceptional', to use Williamson's preferred terminology. Logical theory is theory, just as theology is theory, just as metaphysics is theory, and so on. This attitude, these days, remains the norm among those theorists advancing nonclassical-logic accounts of paradoxes, just as it remains the norms among their classical-logic neighbors.

On the other hand, there is no point in 'debating' whether logic is nonclassical without an account of what the role of the relation - namely, logical consequence - is supposed to be. Nobody rejects that in mathematics any relation looking enough like 'a logic' can be studied 'as logic', and that we should evaluate research projects in logic along standard pragmatic methodology. ${ }^{3}$ But nobody is debating any of that.

The debate between classical-logic and nonclassical-logic accounts of strange phenomena (for present purposes, truth-theoretic paradoxes) requires a stand on the role of the relation - namely, 'logical consequence' - at issue. Exactly which role is at issue in all such debates is well beyond the scope (and interest) of this paper. For present purposes I take a stand on the given role that is compatible with Williamson's new Quinean argument: I treat logical consequence as one among (very) many formal entailment relations, and in particular as a closure relation on theories, where 'closure' requires its usual properties - properties reflecting the standard 'reflexivity', 'monotonicity' and 'transitivity' of logical consequence (herein understood). ${ }^{4}$ To be a

\& Restall [12] and many, many others since.) But I flag this point just to set it aside. Williamson doesn't rehearse the territory (no reference to Anderson or Belnap) but he explicitly takes account of it.

${ }^{3}$ And, of course, much else goes into logic qua (roughly four-fold) mathematical discipline, and similarly (though more narrowly) within philosophical logic (qua philosophicalcum-mathematical discipline outside of mathematics). Beall \& Burgess [11] provide a concise summary of the terrain of contemporary logic.

${ }^{4}$ More clearly: I assume - with Williamson - that the consequence relations satisfy their standard properties of reflexivity, monotonicity and transitivity in such a way that the resulting closure operator or consequence operator on theories has its usual closure properties - extensiveness, increasingness, and transitivity (in the usual way). This rules out a lot of candidates for logical consequence, but my focus here is on Williamson's discussion - and he rules them out too.

Australasian Journal of Logic (16:7) 2019, Article no. 2 
closure relation (on a theory) is to be a relation that, in addition to having standard closure properties (above), 'completes' the theory by churning out all of the consequences of the theory - consequences according to the given closure relation. To be a formal closure relation, for present purposes, is to do such completion work in terms of 'forms', where the relevant 'forms' are individuated by select vocabulary in very familiar ways.

But none of that specifies logical consequence. There are many, many, many entailment relations that are closure relations. Debates whether logical consequence is nonclassical presuppose a prior answer: which of the many closure relations is logical consequence? The answer points to logical vocabulary in terms of which logical forms are defined.

\subsection{Logical vocabulary as familiar De Morgan}

Here, I have no new arguments to specify the exact features of logical vocabulary. As a result, I have no new arguments for the claim that I assume for present purposes: namely, that logical consequence is the closure relation whose forms are individuated by the standard first-order vocabulary (shy of identity). ${ }^{5}$ Still, I join the many in taking the standard batch of logical vocabulary to be 'universal' and 'topic-neutral' in a sense waved at by Williamson, when he notes (in a different context) that

$[A]$ ny complex scientific theory, especially one that involves some mathematics, will make heavy use of negation, conjunction, disjunction, the quantifiers, and identity. [47, p.340]

And that's correct. In what follows, I take logical vocabulary to be involved in all of our true (closed) theories - our as-complete-as-possible true theories.

I should also note that one need not think that entailment requires heavy-duty truth, heavy-duty necessity or so on. As today's philosophical proof theorists will attest there are many proof-theoretic 'descriptions' of entailment relations. I don't intend to take sides on that issue any more than Williamson's discussion does, and Williamson's discussion intends not to take sides on the issue at all. (This isn't to say that I don't rule out certain candidate relations in what I say (I absolutely do, as above); it's just that taking them to be entailment relations isn't supposed to rule them out due to issues of weighty notions of 'truth preservation', 'necessity' or so on.)

${ }^{5}$ Williamson treats identity as being in the standard bag of logical vocabulary, but this item has been a controversial ingredient, and in any event is unnecessary for present purposes. (My view is that identity relations are always theory-specific, but I set these wider debates aside.)

Australasian Journal of Logic (16:7) 2019, Article no. 2 
Except for identity, which I take to be a theory-specific issue of individuation (among other things), Williamson's standard bag of vocabulary is what I assume to be logical vocabulary - the vocabulary in terms of which the logical forms (i.e., the 'forms' recognized by logical consequence) are given. ${ }^{6}$

Just to be explicit, the standard logical vocabulary (herein, the logical vocabulary) consists of a pair of unary connectives, a pair of binary connectives, and two quantifiers - all pairs interpreted to contain 'duals' of each other, namely:

- The (redundant) truth operator: it is true that.... ${ }^{7}$

- The falsity operator (negation): it is false that....

- Conjunction: ...and....8

- Disjunction: ...or....

- Universal quantifier: Every object is such that....

- Existential quantifier: At least one object is such that...

Demanding that these pairs of connectives contain duals is a demand on their behaviour (with respect to the consequence relation). And that's generally where rival theories of logical consequence differ. For my purposes in this

\footnotetext{
${ }^{6}$ Obviously, the term 'logical form', like the term 'logical constants', is often used to pick out any specification of vocabulary used to define 'forms' for the (formal) consequence relation. This is fine as far as terminological choices go. But if our concern is whether we should reject nonclassical-logic positions we should first settle on the role of the relation namely, closure - and its details (i.e., which vocabulary defines the forms, etc.). That's all I'm sketching here. For recent debate on both logical vocabulary and its relation to logical form see Gil Sagi's work [42]; Sagi's work challenges some of the assumptions of this paper but, for purposes of the current paper (but only for such purposes), I set the challenges aside.

${ }^{7}$ This is logically redundant - it is always treated as the null operator, taking a sentence and delivering a logically equivalent (and everywhere intersubstitutable) sentence - and, so, standardly left off the list. I mention it here only to complete the symmetric picture of duals.

${ }^{8}$ This is sometimes useful to express using the truth operator, just to distinguish from tense-intensive conjunctions (e.g., 'dynamic' conjunctions). One can think of the target (logical) conjunction as It is true that... and it is true that....
}

Australasian Journal of Logic (16:7) 2019, Article no. 2 
paper I treat the connectives as duals in the usual - and very traditional De Morgan sense, where the falsity operator (viz., negation) takes the dual of a sentence to its dual (of duals, etc.): $\neg$ takes $A \wedge B$ to $\neg A \vee \neg B$; and $\neg$ takes $A \vee B$ takes to $\neg A \wedge \neg B$; and $\neg$ takes $\neg A$ to $A$; and so on.

On this approach to logical vocabulary (including its behaviour) many rival theories of logic (-al consequence) are ruled out. I am in no way offering a stand-alone argument for this approach; I am simply putting it on the table as a concrete example of one 'live' and familiar theory of logical consequence that is very much at stake in Williamson's new Quinean argument against nonclassical logic.

\subsection{Classical and subclassical}

To focus discussion let us zero in on exactly two candidate accounts of logical consequence (so understood so far): namely, classical and FDE (reviewed below). ${ }^{9}$ What is important to note is that both the classical account (viz., classical logic) and the subclassical account (viz., FDE) completely agree on three things:

1. Logical Vocabulary: the vocabulary is the standard trinity of pairs (viz., the two unary, two binary, and two quantifiers).

2. 'Interpretation' of Vocabulary: each pair contains duals (as in $\S 1.1$ and sketched below).

3. Consequence is a Closure Relation (standardly understood).

Both candidates - the classical and given subclassical - can enjoy similar 'semantics'. (This is not to privilege 'semantics' or model theory over proof theory; it's just that presentation of the former is vastly easier than the

\footnotetext{
${ }^{9} \mathrm{FDE}$ ', for 'first-degree entailment', has come to be the tag for the target logic, of which other well-known subclassical logics - for example, LP [3, 32] and K3 [27] and S3 $[1,2,20]$ - are proper extensions, and of which classical logic is the 'top' extension. (S3, so called by Field for 'symmetric 3' [20], is what you get if you add a rule to FDE according to which every formal contradiction $p \wedge \neg p$ entails - as a consequence - every instance of the dual form $\neg q \vee q$. (Adding double-negation equivalence to what Urquhart [44, 45] labeled 'Ockham logic' results in FDE.)) All such common candidates agree on logic's heart: namely, De Morgan behaviour. I note that there's a narrower (and original) use of 'FDE' by some relevance (aka 'relevant') logicians [17, 28, 31, 37], but the broader usage is fairly standard [13, 34]. FDE was prominently studied by Belnap [15] and Dunn [18, 19].
}

Australasian Journal of Logic (16:7) 2019, Article no. 2 
latter in non-specialist settings.) In particular, we can think of the semantics along the lines of Dunn [18], using very familiar true-in-M and false-in- $M$ relations: ${ }^{10}$

- Atoms: ${ }^{11}$

○ Exhaustion: either $M \models_{t} p$ or $M \models_{f} p$, for every model $M$ and every atom $p$.

o Exclusion: either $M \nvdash_{t} p$ or $M \nvdash_{f} p$, for every model $M$ and every atom $p$.

- Truth/null operator $(\dagger)$, for any model $M$ and sentence $A$ :

○ $M \models_{t} \dagger A$ iff $M \models_{t} A$.

○ $M \models_{f} \dagger A$ iff $M \models_{f} A$.

- Falsity/negation operator $(\neg)$, for any model $M$ and sentence $A$ :

○ $M \models_{t} \neg A$ iff $M \models_{f} A$.

○ $M \models_{f} \neg A$ iff $M \models_{t} A$.

- Conjunction $(\wedge)$, for any model $M$ and sentences $A, B$ :

$\circ M \models_{t} A \wedge B$ iff $M \models_{t} A$ and $M \models_{t} B$.

○ $M \models_{f} A \wedge B$ iff $M \models_{f} A$ or $M \models_{f} B$.

- Disjunction ( $\vee$ ), for any model $M$ and sentences $A, B$ :

$$
\begin{aligned}
& \circ M \models_{t} A \vee B \text { iff } M \models_{t} A \text { or } M \models_{t} B . \\
& \circ M \models_{f} A \vee B \text { iff } M \models_{f} A \text { and } M \models_{f} B .
\end{aligned}
$$

\footnotetext{
${ }^{10}$ Here, I ignore the quantifiers and object variables not because they're unimportant or particularly difficult; I ignore them because their treatment is mirrored by the treatment of conjunction and disjunction, and there is nothing special about Williamson's argument that turns on the quantifiers versus the simpler propositional level. Note that Dunn famously pointed to a simple many-valued semantics wherein one takes the set of semantic values to be the powerset $\wp(\{t, f\})$ of the usual classical set $\{t, f\}$, taking every t-containing value to be designated - 'preserved' in validity.

${ }^{11}$ In what follows I don't specify how models 'make true' or 'make false' atoms, but the story is the absolutely standard one in terms of (anti-) extensions and denotation. (Also, notation-wise, $M \forall_{i}$ is the negation of the given truth-/falsity-in-M relation.)
}

Australasian Journal of Logic (16:7) 2019, Article no. 2 
And logical consequence is then defined as usual: a set $X$ logically entails a sentence $A$ iff every model $M$ that 'makes true' everything in $X$ (i.e., $M \models_{t} B$ for all $B \in X$ ) is one that likewise makes $A$ true.

Note that if both exhaustion and exclusion are imposed then logical consequence is exactly as classical-logic theorists say: namely, classical logic. If neither exhaustion nor exclusion is imposed then logical consequence is exactly as FDE theorists say: namely, FDE. In the latter case, there are no logical truths (i.e., sentences that are true in all 'possibilities' - all models recognized by logical consequence), but all De Morgan interaction remains. In the former (classical-logic) case, all De Morgan interaction remains, but there are the usual (classical-logic) stock of logical truths.

For present purposes we focus on these two candidates alone: classical and FDE. But worth noting is that commonly cited subclassical candidates LP and K3 - both of which are explicitly highlighted by Williamson - differ on the two key constraints (viz., exhaustion and exclusion): the former rejects that logic allows 'gaps' (i.e., LP maintains that logic demands exhaustion) but accepts that logic allows 'gluts' (i.e., LP rejects that logic imposes exclusion); and the latter rejects that logic allows gluts (i.e., K3 maintains that logic demands exclusion) but accepts that logic allows gaps (i.e., K3 rejects that logic imposes exhaustion). The FDE theorist enjoys the more elegant and symmetric position: namely, that logic demands neither exhaustion nor exclusion; it demands only the given De Morgan interaction in its vocabulary. And classical logic enjoys an equally elegant and symmetric position as compared with LP or K3: namely, that logic demands both exhaustion and exclusion, in addition to the central De Morgan interaction.

\subsection{Logic as universal closure}

So go the two main candidates for logical consequence (at least for purposes of this paper). But what, if anything, is special about logical consequence versus the many other formal closure relations on our true (closed) theories?

On the view assumed herein, logical consequence is the universal - 'basement level' - closure relation involved in all of our true (non-empty) theories. It is the unique formal closure relation involved in all of the extra-logical closure relations of our many true (hence, non-empty) theories - physics, biology, algebra, theology, category theory, metaphysics, chemistry, epistemology, neuroscience, etc. All such true theories - systematized and expanded as completely as possible - have closure relations that include, at the bottom-

Australasian Journal of Logic (16:7) 2019, Article no. 2 
level, logical consequence. In this way there's an obvious sense in which no true theory transgresses logic: each such theory is closed under logic.

Of course, we can talk about the theory-specific, extra-logical closure relations of our many theories as 'the logics of the theories' if we wish (the 'logic of sets', 'the logic of possibility', 'the logic of permissibility', 'the logic of part-whole' etc.); it does no serious harm whatsoever, and even isolates an important pattern of inquiry. But if we're debating whether logic is classical or nonclassical it behooves us to be clear about the particular closure relation we are debating. And that's where Williamson's new Quinean argument comes in, and where my discussion is focused.

I do not see this view as conflicting with anything that Williamson says in his new Quinean argument; but it is definitely a view at stake in his argument. I repeat that I join Quine and many others - including Williamson in said paper - in being (to use Williamson's term) 'antiexceptionalist' about logic. Theories of logical consequence are to be treated as other theories, enjoying no special epistemic or metaphysical or physical or theological or political priority over any other theory. This is the dominant view among active nonclassical-logic theorists, and I endorse it.

Still, such 'antiexceptionalism' is perfectly compatible with the target relation's having an exceptional role in our theories. The exceptional role that I highlight, for purposes of this discussion, is logic's basement-level position in all of the many closure relations involved in our many true theories. On this view, no true theory has a consequence relation - a closure relation that bucks logical consequence; they all conform to the simple De Morgan demands of the sparse logical vocabulary. But logic is special in that way. The consequence relations of two theories generally don't accommodate what the other demands, largely for the boring reason that the extra-logical vocabulary involved in the (theory-specific) consequence relation is absent from the other. But logical vocabulary, as Williamson and a very long tradition attest, is different: it is 'topic-neutral' and 'universal' in its ubiquity among all of our systematic true theories.

In what follows, I shall take logic to be as above: the basement-level universal closure relation involved in all of our true (non-empty) theories, whose 'forms' are the usual first-order forms shy of identity. And for simplicity, for present purposes, there are exactly two candidates: the classical candidate and the given subclassical candidate (viz., FDE). ${ }^{12}$

\footnotetext{
${ }^{12}$ While I do endorse the given view of logical consequence, I do not believe that these
} 


\section{$2 \quad$ Williamsonian Quine sans conservatism?}

Though the argument is intended to generalize to strange phenomena of any sort, Quine's familiar argument against nonclassical logic (a fortiori, against FDE), as quoted by Williamson [47, p. 340], focuses on paradoxes:

The classical logic of truth functions and quantification is free of paradox, and incidentally it is a paragon of clarity, elegance, and efficiency. The paradoxes emerge only with set theory and semantics. Let us then try to resolve them within set theory and semantics, and not lay fairer fields to waste [36, p. 85].

Of course, 'clarity, elegance, and efficiency' alone don't go that far. After all, as Robert K. Meyer emphasized [30], the absolute clearest, most elegant, and most efficient system (in terms of axioms, rules, and power of output!) is his 'pure system of irrelevance', which enjoys a single axiom $p$ and a single rule of substitution for any sentential variable (including, of course, $p$ ). This account of logical consequence has a beautifully simple description (just given); and it's sufficient to deliver every truth expressible in the language of any theory. But it goes overboard. It delivers the trivial theory - the set of all sentences of the language of our theory, for any theory we may come up with.

The trivial theory is to be rejected by all lights - be they glut theorists, gap theorists, or your run-of-the-mill classical-logic theorist. And Williamson's new argument is sensitive to such a broad crowd; it is aimed at accommodating the FDE account (and explicitly so for extensions thereof). Where Quine's argument goes wrong - and this is not obvious from the quoted bit above - is that Quine's central premise simply rules out the FDE account (and nonclassical accounts generally). ${ }^{13}$ Quine's central premise is really twofold:

p1. Classical logic is the status quo, 'the logic', as Williamson paraphrases, that 'we more or less currently accept' [47, p. 338].

exhaust the family of the most viable candidates. But my aim here is not to argue for a particular candidate so much as defend the subclassical family against Williamson's new Quinean argument.

${ }^{13}$ Notoriously, in the same work, Quine goes from Quine-the-Good (viz., a champion of pragmatism about logical theory) to Quine-the-Bad (viz., one who says that any logical theory that deviates from the classical one is 'changing the subject'). Williamson makes abundantly clear that he is not walking that notorious road; he explicitly aims to accommodate the nonclassical theorist - including our running FDE theorist - rather than rule her out with a conservatism principle against the nonclassical theory.

Australasian Journal of Logic (16:7) 2019, Article no. 2 
p2. Conservatism: hold to the status quo unless there is sufficient payoff in exchange for 'change' (e.g., FDE).

The next premise - which I here bracket out - is that there is not sufficient payoff, and in fact that there's significant loss (notably, explanatory loss) in 'changing' to FDE (where it really is a change if p1 is correct). Williamson argues explicitly for this premise by putting forward an objection against the FDE candidate (and other subclassical candidates); but I address his objection from explanatory loss in $\S 4$, only after addressing his key claim to improve on Quine by doing without Quine's conservatism.

Williamson endorses p1 but explicitly rejects p2. I address each in turn, though the crux of my argument against Williamson's claim to be free of Quine's conservatist premise concerns p2.

\subsection{Classical logic as status quo}

Is the classical account the status quo in Williamson's sense - namely, 'the logic we more or less currently accept' [47, p. 338]? Well, the question demands a prior answer: accept as what? For present purposes, the target role of logic is as the universal closure relation involved in the closure relations of all of our (non-empty) true theories. I admit that the status quo in intro-logic classes is something more or less equivalent to classical logic; but it strikes me as highly controversial whether those (few?) philosophers who've competently reflected on the range of candidates are in agreement about classical logic's playing the given universal-closure role. In fact, if anything, the opposite may well be right - namely, that the status quo regarding the given role is different from classical logic. (And I am confident that Williamson does not intend to invoke the many philosophers who were taught nothing except classical logic and thereby understandably have no competent grasp of other candidates.)

Perhaps I am simply mistaken, unable to see the firmly settled conclusions of a vast majority of the many; but I do not see the mistake. The position behind p1 demands empirical work, or at least more of an argument than the claim that classical logic is the status quo (so understood).

Despite the serious reservations about p1 I nonetheless grant the premise for purposes of Williamson's new Quinean argument.

Australasian Journal of Logic (16:7) 2019, Article no. 2 


\subsection{Strength...sans conservatism?}

The problem with Williamson's argument centers on his would-be replacement for Quinean conservatism. Williamson rightly observes that Quine's conservatism simply rules out the FDE theorist - at least granting p1, which is herein granted. But without conservatism, how does one argue for 'maintaining' - 'not changing' - classical logic? Williamson invokes strength.

\subsubsection{Strength as Post-completeness}

The principal - and clearest - sense of strength that Williamson invokes is Post-completeness (at least at the propositional level), where this can be thought of as the very edge of falling into Meyer's pure calculus of irrelevance. In particular, classical (propositional) logic is Post-complete in the sense that if you were to add any other (non-vacuous) axioms (or the effect of such axioms in the shape of rules) the system would simply be equivalent to Meyer's pure calculus of irrelevance, at least in terms of output: namely, it would take every theory to the trivial theory.

Williamson's new Quinean argument against FDE replaces conservatism with strength qua Post-completeness (at least at the propositional fragment).

The problem is that 'strength' does not help unless Quine's conservatism about 'keeping classical logic' is in force - or at least something close to it. After all, why think that Post-completeness is a virtue of the universal, basement-level closure relation? The FDE theorist rejects that Postcompleteness is a virtue. Why? Answer: the FDE theorist rightly notes that Post-completeness precludes not only the (logical) possibility of true glutty theories but similarly true gappy (prime) theories. ${ }^{14}$

Williamson might retort that Post-completeness is a virtue of logical consequence (qua given closure relation) if there are no possibly true glutty or gappy theories of the sort recognized by (the models of) FDE. And that might be right, of course; but Williamson's argument - sans Quine's conservatism - offers no reason to rule out such possibilities, certainly none that don't commit Quine's sin of simply ruling them out from scratch. In this

\footnotetext{
${ }^{14} \mathrm{~A}$ theory is said to be prime iff it contains the logical disjunction of two sentences iff it contains at least one of the disjuncts. According to classical-logic theorists, many of our true (and as complete as possible) theories are not prime. (I briefly return to this point in connection with a looser and secondary sense of 'strength' that Williamson's new Quinean argument gestures at.)
}

Australasian Journal of Logic (16:7) 2019, Article no. 2 
way, Williamson's new Quinean argument does no better than Quine's original argument as far as accommodating its target (and very much live-option) subclassical candidates.

Williamson [47, p. 337] rightly notes in passing that FDE theorists (and, generally, other well-known subclassical-logic theorists) reject that Postcompleteness is a virtue of logical consequence (understood as universal closure, as above). Williamson mentions, without citing, the idea that weakness, according to some such theorists, is a virtue because weaker-than-classical logic affords exploration of various theories - glutty ones, gappy ones, mixed ones, etc. ${ }^{15}$

Let us suppose that the FDE theorists claims that her account of logic has the virtue of weakness so understood - namely, that it allows for the exploration of said (nonclassical and nontrivial) theories. Williamson's argument against this idea is a slippery slope:

In discussion of alternative logics, it is not always recognized that strength [Post-completeness] is a strength, in logical theories as in others. [NB: it is not clear what Williamson means by 'as in others', since he seems to be talking about extra-logical theories in other non-logical disciplines; but the idea of Post-completeness doesn't apply to those in any clear sense. But I set this aside.] One often encounters various forms of exceptionalism about logic, according to which weakness is a strength [i.e., virtue] in logic, because weak logics leave open more possibilities, prejudge fewer issues, and achieve higher levels of neutrality. However, such tendencies have no natural stopping-off point short of an empty consequence relation, since any logical principle whatsoever is in principle open to challenge. Indeed, virtually every salient logical principle has actually been challenged by some philosopher or other. [47, p.337]

Before arresting the (alleged) slippery slope let me set aside Williamson's remark about 'various forms of exceptionalism about logic'. Perhaps there are logical theorists who are 'exceptionalists' in a bad way - and not just in being clear about the exact role of the relation under discussion. If there are such

\footnotetext{
${ }^{15}$ Williamson cites no work in the given remarks, but one such view is advanced by Beall $[9,10]$. Routley [39] also exhibits the spirit of this sort of view, and Meyer and Routley do too $[40]$.
}

Australasian Journal of Logic (16:7) 2019, Article no. 2 
theorists, I join Williamson in thinking that their view should be rejected in favor of the widely dominant Quinean pragmatism. But the 'exceptionalism' that Williamson flags (without explaining) need not play any role in whether Williamson's slippery-slope argument is viable against our FDE theorist.

The problem with Williamson's slippery-slope is twofold. First, and most clearly, even by Williamson's own lights (which require the standard 'structural rules' of logical consequence), logical consequence must be reflexive in the standard sense: namely, that $A$ logically entails $A$, for all $A$ in the language of any theory. ${ }^{16}$ So, the empty consequence relation is ruled out as a serious candidate right from the get-go. And so the slippery slope is arrested shy of the would-be empty relation.

Second, and most important, the slippery slope suffers from the defect of most slippery-slope arguments: it is implausible given our starting point. Recall that '[i]n discussion of alternative logics' we agree that debate is pointless unless we zero in on a particular role for the relation. For present purposes I have zeroed in on the role of universal closure relation - reflecting the long tradition of thinking of logic as 'universal', 'topic neutral', and enjoying standard closure properties (properties that Williamson implicitly endorses in his discussion). And there is a starting-point core there beyond the required closure-relation properties. The FDE theorist - like any subclassical theorist - agrees with the classical theorist that there's a logical core: namely, De Morgan behaviour (over the standard stock of connectives). And it's at this and only this level of weakness where the FDE theorist claims (we are imagining for the sake of Williamson's slippery-slope) that there's a virtue; she (rightly) says that the given weakness accommodates exploration of important (De Morgan-satisfying) glutty and prime gappy theories. Williamson's argument suggests that such a theorist must - by parity of reasoning (?) - be open to even those theories that buck De Morgan behaviour among the standard connectives, and indeed cannot stop even when one reaches relations that are no longer closure relations - such as the empty relation.

But why? The supposed weakness-as-virtue claim isn't - for all that Williamson's argument says - that the weaker the universal closure relation is, the better the universal closure relation is. (If that really is the claim, then I agree with Williamson that it's a claim in desperate need of support.

\footnotetext{
${ }^{16}$ Since logical consequence is a set-sentence relation, 'reflexivity' isn't exactly the right term, but we all know what is meant - as reflected in the usual practice of dropping set notation when dealing with sentence-sentence instances of logical consequence.
}

Australasian Journal of Logic (16:7) 2019, Article no. 2 
On the surface, it's palpably implausible. But Williamson fails to cite any examples.) Presumably, the spirit of Williamson's 'strength is a strength' is not to be read in the same light: namely, that the stronger the universal closure relation is, the better the universal closure relation is. (That reading leads to Meyer's pure calculus of irrelevance, which presumably is ruled out.) There are limits to the slope, and for present purposes the bottom limit is De Morgan behaviour. What the FDE theorist advances by saying that weakness - in this case - is a virtue is that traditional De Morgan behaviour is respected while allowing for true glutty and gappy theories. There is no plausible position according to which weakness - in and of itself - is a virtue, any more than, as above, strength by itself is a strength.

Williamson's key (or, again, at least clearest) notion of strength is Postcompleteness. But why stop there if strength is a strength? The reason, of course, is that not anything goes - even if, as Williamson notes, "virtually every salient logical principle has actually been challenged by some philosopher or other'. The reason for stopping at Post-completeness is that going beyond distorts the role at issue: namely, universal closure (respecting traditional De Morgan). All of this - including the standard closure properties - can and has been challenged; ${ }^{17}$ and while all such beyond-closure or beyond-DeMorgan projects are interesting and fruitful in both mathematical and philosophical ways, there's little point in debating alternative logics without taking a firm stand somewhere.

Just because philosophers have or might question a principle - be it in logic or any other theory - doesn't thereby remove the warrant we have in the principle. That's what we learned from the pragmatists; that's what we learned from Descartes' unfortunate quest for foundations - valuable as that episode was in other respects. And the place where Williamson puts his own stand is a De Morgan closure relation standardly understood, one shy of both the trivial consequence relation and the anti-trivial one (which wouldn't even be a closure relation if we are restricted to non-empty theories). The FDE theorist puts her stand at the same core: De Morgan interaction. She rightly notes that the weakness of FDE vis-a-vis the classical-logic account has the virtue of accommodating possibly true glutty and gappy theories. She does not claim that weakness is a virtue in and of itself; and that every imaginable fiction about logic needs to be accommodated.

\footnotetext{
${ }^{17}$ Indeed, Rohan French makes a case for dropping reflexivity [21], while a host of others question variations of transitivity or contraction or more [29, 35, 38, 43, 46, 48].
}

Australasian Journal of Logic (16:7) 2019, Article no. 2 
I conclude that Williamson's slippery-slope argument against our candidate FDE account fails to land on its mark. This leaves us without an argument from strength - conceived as Post-completeness - against the FDE account. Of course, re-invoking Quine's conservatism premise (viz., both p1 and p2) would change everything; but it would only take us back to Quine's original argument which failed to accommodate the FDE theorist as a genuine candidate - something Williamson's argument (laudably) tried to do.

\subsubsection{Strength as increased information?}

Williamson does offer another replacement for Quine's conservatism premise, one based on a very different - and, alas, much looser - notion of strength. This is a notion of 'information strength' but not the formal one involved in familiar theories of information strength. Instead, this is an informal notion illustrated by two theories that are (negation-) inconsistent (i.e., one entails, by the theory's closure relation, the logical negation of the other) but one is 'stronger' in the sense of being 'more specific or informative' [47, p. 336]. Williamson illustrates:

For instance, 'The time is between 3.14 and 3.16' is more specific than 'The time is between 4.00 and 12.00', even though they are inconsistent with each other.... One role for the informal scientific standard of strength is to provide a minimal threshold of informativeness below which theories do not even come up for serious abductive evaluation. We want scientific theories to inform us about their subject matters; weak theories do too little of that to give us what we want. [47, p. 336]

Williamson gives one other illustration (an 'extreme' one, he thinks) involving axiomatized theories in the same language that are jointly logically inconsistent - one a conjunction of universals, the other the negations of those universals - but each theory consistent. The negation-ful theory is less informative in the way that a list of negated universals is less informative than the unnegated list of universals.

The target notion of strength remains imprecise, and Williamson acknowledges as much. ${ }^{18}$ The question is whether this imprecise notion helps tilt

\footnotetext{
${ }^{18}$ Williamson uses the notion to argue directly for the informal strength (in the running sense) of a classical-logic-based theory over the intuitionist-logic counterpart. The
}

Australasian Journal of Logic (16:7) 2019, Article no. 2 
against the FDE theorist, as Williamson suggests that it does. I don't see that it does. In fact, it strikes me as tilting against the classical-logic account towards the FDE (or at least K3) account.

Williamson puts forth his secondary sense of strength to give 'a minimal threshold of informativeness below which theories do not even come up for serious abductive evaluation.' Notwithstanding missing details, the given desideratum is a good one. But it also has a flip side. In particular, we do not want too much informational clutter: we do not want to be dealing with theories that are about things extraneous to the theory. This is why primeness of theories is important. We do not want our theory to be talking at all about $q$ unless our theory takes a stand on $q$ - for example, that $q$ is true, that $q$ is false. But the classical-logic account of our universal closure relation demands that our theories have extraneous information: they one and all talk about whatever $q$ is about for every expressible $q$ in the language, even if the theory takes no stand on the truth (similarly, falsity) of $q$. In short, the classical-logic account, unlike the FDE account, rules out the possibility of true but negation-incomplete prime theories, and in this way always tows around an extraneous load of information - one that goes above the maximum threshold of informativeness.

Williamson might respond that logical truths like instances of excluded middle are not informative at all, and so do not add informational clutter. Even so (a matter I grant here only for efficiency), why clutter the theory with such claims when - for example, in the case of excluded middle (though it applies across the board) - the theory takes no stand on either disjunct, and would be more-to-the-point if it were a prime theory? Without a more precise account of the virtuous levels of information our theories are to take, Williamson's secondary sense of strength falls short of tilting against the FDE account.

argument just mirrors the 'extreme' illustration Williamson gives about the axiomatized theories; but it's successful only if intuitionists take the sort of stand on propositional quantification that Williamson suggests. I have no view (at all) on that particular debate, except to say that it strikes me as implausible that intuitionists should naturally adopt the approach to propositional quantification that Williamson's argument assumes. (After all, propositional quantification often - though not necessarily - aligns with very thin notions of truth in a way that intuitionist notions of 'truth as proof' (to speak crudely) would not. So, there's room for intuitionists to balk at Williamson's invocation of such quantification in the context. But, again, I leave this aside as an interesting but tangential matter.)

Australasian Journal of Logic (16:7) 2019, Article no. 2 


\subsection{Summary evaluation of the new Quinean argument}

Quine's familiar argument against the FDE (and every other nonclassical) account of logical consequence simply rules out such 'alternatives' from scratch; that's the effect of Quine's twofold premise of $\mathrm{p} 1$ and $\mathrm{p} 2$.

Williamson aims to do better by presenting a new Quinean argument stripped of Quine's problematic p2 (and stripped of Quine's notorious changing-topic claim). Williamson's replacement for Quine's p2 points to 'strength' in two different senses, a precise one and an imprecise one. Neither sense of 'strength' serves to give a viable new Quinean argument against our representative nonclassical account of logic (viz., FDE). The former sense rules out FDE from scratch - and so commits the same sin as Quine's original p2 - or it is left in need of independent support. And the latter (imprecise) sense of 'strength' is backed only by a slippery-slope argument that fails on at least two (discussed) fronts.

I conclude that Williamson's new Quinean argument against nonclassical logic fails. ${ }^{19}$

\section{The supplemental severe-testing argument}

Of his new Quinean argument, which I have argued fails to undermine an FDE (or similar subclassical) accounts of logic, Williamson notes that it can be strengthened by the 'track record of classical logic':

The strong prima facie abductive case for classical logic just noted [i.e., from strength] does not depend on a principle of conservatism. It does not rely on the position of classical logic as the status quo, the logic we more or less currently accept, nor does it appeal to the benefits of familiarity or the costs of change.

\footnotetext{
${ }^{19}$ Gillian Russell [41] argues that neither sense of 'strength' is a virtue or a vice of a logical theory - and hence neither a virtue of the classical-logic account nor a vice of the FDE account, and similarly is neither a vice of the classical-logic account nor a virtue of the FDE account. If Russell is correct at least about the non-strength conclusion then all the worse for Williamson's new Quinean argument. Of course, if she's also correct about the non-vice conclusion then all the worse for those - including this author - who think that FDE's weakness (where it stands) is a virtue. I am not convinced that Russell's conclusions are correct but for present purposes I bracket them only to show that Williamson's argument does not refute the nonclassical accounts any more than Quine's notorious argument does.
}

Australasian Journal of Logic (16:7) 2019, Article no. 2 
It concerns intrinsic features of classical logic, such as simplicity and strength, which it would have even if we currently accepted some non-classical logic [such as FDE]. The case may indeed be strengthed by reference to the track record of classical logic: it has been tested far more severely than any other logic in the history of science, most notably in the history of mathematics, and has withstood the tests remarkably well. Nevertheless, the initial abductive case for classical logic would be quite powerful, even if we had only stumbled across that logic a few weeks ago.

Williamson doesn't elaborate on the 'severe testing' that classical logic has undergone; but the idea, I assume, is that many of our true theories appear to be closed under classical logic - that is, the logical vocabulary appears to behave precisely as classical logic predicts.

For the sake of debate (but, in truth, also for the sake of truth) let me grant that many of our true theories are just so: they appear to be closed under classical logic. Is this a problem for our representative nonclassical account (viz., FDE)? Details are ultimately needed for a final answer. Still, even in general, I agree that Williamson's severe-testing argument does impose a prima facie challenge to the FDE theorist. In particular, the FDE theorist needs to explain how, despite the weakness of logic itself (demanding no more nor less than familiar De Morgan interaction over its connectives), many of our true theories appear to be closed under classical logic - and not just thereby closed under FDE. ${ }^{20}$ The prima facie challenge is to explain such appearances.

How does the FDE theorist explain the ubiquity of true theories that are apparently closed under classical logic? The answer, not surprisingly, points to the theories themselves, and in particular the extra-logical consequence relations of those theories. ${ }^{21}$ Logic (-al consequence) is the universal closure relation on our true (non-empty) theories. But the construction (or, if

\footnotetext{
${ }^{20}$ If a non-empty theory is closed under classical logic then it's thereby closed under every subclassical logic.

${ }^{21}$ Williamson takes up this idea in a different objection from 'explanatory loss' (see $\S 4$ ), though not in relation to the current severe-testing argument. Unfortunately, Williamson doesn't cite any theorists who actually address these concerns, but presumably he has in mind the likes of Beall $[5,7,8]$ and possibly very passing remarks by Humberstone [26]. These are concrete examples of nonclassical theorists addressing the severe-testing argument, but of course the idea is common through most work on subclassical-logic accounts.
}

Australasian Journal of Logic (16:7) 2019, Article no. 2 
you prefer, discovery) of such theories requires construction (or discovery) of extra-logical closure relations that are specific to the theory. Obvious examples: logic (qua universal and topic-neutral closure relation) is silent on all but its vocabulary, and hence silent on the special theory-specific vocabulary of arithmetic, epistemology, etc. Logic doesn't say anything about whether, for example, it is known that $P$ entails $P$. That's a matter for theories of knowledge. And so on. Moreover, logic, according to the FDE account, doesn't tell you whether an arbitrary contradiction! $A$ (shorthand for $A \wedge \neg A$ ) entails every sentence $B$, or dually whether $; A$ (shorthand for $A \vee \neg A$ ) is entailed by every sentence $B$. That, on the FDE account, is a theory-specific matter; logic itself - qua topic-neutral, universal closure relation - demands only the core De Morgan behaviour.

Are there common ways of constructing the given extra-logical closure relations that result in the effect of classical-logic closure? Yes. Details depend on the subclassical account, but a very simple one invokes 'shriek' and 'shrug' rules. ${ }^{22}$

To shriek a predicate $P$ in a theory is to impose the following condition on the theory's consequence relation: ${ }^{23}$

$$
\exists x(P x \wedge \neg P x) \vdash_{T} \perp
$$

where $\perp$ is some sentence in the language of $T$ which, according to the theory's closure relation $\vdash_{T}$, entails all sentences in the language of $T$. The effect of shrieking $P$ is to reduce the theory's models in such a way as to ignore the many glutty models that logic itself otherwise allows. If one shrieks all predicates in the language of theory one thereby reduces the models of the theory to non-glutty ones - and, hence, one thereby has the theoretical impossibility of gluts. A theory is shrieked (simpliciter) if all of its predicates are shrieked.

To shrug a predicate $P$ in a theory is to impose the dual of shrieking: ${ }^{24}$

$$
\top \vdash_{T} \forall x(P x \vee \neg P x)
$$

\footnotetext{
${ }^{22}$ These ideas are aired by Belnap \& Dunn [16], aired against by Priest [33], but refined and advanced by Beall [5, 6, 9].

${ }^{23}$ The 'shriek' terminology just follows the common abbreviation '! $A$ ' for ' $A \wedge \neg A$ ', where '!' is often called 'shriek'. (Others call it 'bang', as Roy Sorensen and Gill Russell independently reminded me.)

${ }^{24}$ The terminology 'shrug' is from Colin McCullough-Benner, who likened excluded middle as a sort of shrug of the shoulders while saying that 'it's at least one of either true and false (but that's all I'm committed to as far as the theory's possibilities/models go)'.
}

Australasian Journal of Logic (16:7) 2019, Article no. 2 
where $T$ is some sentence in the language of $T$ which, according to the theory's closure relation $\vdash_{T}$, is entailed by all sentences in the language of $T$. The effect of shrugging $P$ is to reduce the theory's models in such a way as to ignore the many gappy models that logic itself otherwise allows. If one shrugs all predicates in the language of a theory one thereby reduces the models of the theory to non-gappy ones - and, hence, one thereby has the theoretical impossibility of gaps. A theory is shrugged (simpliciter) if all of its predicates are shrugged.

How, then, does the FDE (or similar subclassical) theorist explain the ubiquity of true theories that are apparently closed under classical logic? She points to the ubiquity of shrieking and shrugging. Such classical-logic behaviour is (as Williamson's challenge notes) 'most notabl[e] in the history of mathematics'. Indeed, it is precisely in mathematical theories wherein the theoretical possibilities - those possibilities modeled by the given theory's models - are always reduced to classical models. All of this is perfectly in line with the idea that logical consequence - qua the universal (topic-neutral) closure relation - is subclassical. ${ }^{25}$

Much more can be said by way of the FDE theorist's response to Williamson's severe-testing argument; but I hope that enough has been said to show that the 'track record of classical logic' in mathematics (and other disciplines) not only can be naturally explained by the FDE account; it already has been explained in various concrete accounts.

\section{Williamson's objection from explanatory loss}

Even though Williamson's new Quinean argument does not fly without resorting to Quine's conservatism (or something similar), Williamson advances a direct objection intended to undermine the FDE account, the objection from explanatory loss. ${ }^{26}$ While part of a specific discussion of responding to

\footnotetext{
${ }^{25}$ Let me emphasize that not all subclassical-logic (certainly not all nonclassical-logic) accounts maintain this 'classical' line about mathematics. (Perhaps the most prominent glut theorist, viz., Graham Priest, does not endorse it.) But it is in no way a minority view, or even close to a minority view. By my lights, it's a very common view among recent subclassical-logic theorists.

${ }^{26}$ I should note that Williamson, in the closing paragraph of [47], takes his various objections to (by implication) FDE to have been neglected by those of us working on paradoxes. This is a very curious claim to make given that much of the work has taken precisely some of Williamson's considerations to be drivers of their various accounts. This
}

Australasian Journal of Logic (16:7) 2019, Article no. 2 
truth-theoretic paradox, the crux of the broader explanatory-loss objection against nonclassical account of logic is this: ${ }^{27}$

$[R]$ estricting classical logic will tend to impose widespread restrictions on its explanatory power, by blocking the derivation of its classical consequences in particular applications. [47, p. 340]

The objection is closely related to the severe-testing argument (see §3) and the FDE theorist's shrieking-shrugging response. As above, the FDE account (or similar subclassical accounts) says that classical logic does not have the explanatory power that Williamson assumes (partly in his assumption of Quine's p1); the explanatory power of our (in-effect) classically closed true theories is via a restriction to classical models for the theories - just as Williamson believes. The derivation of such classical consequences is as it always appears: namely, that arbitrary $B$ follows from arbitrary ! $A$ in the theory; that $A \wedge(A \rightarrow B)$, where $\rightarrow$ is logic's material conditional defined as usual (viz., $\neg A \vee B$ ), has $B$ as a consequence; and that arbitrary i $A$ is a consequence of arbitrary $B$; and so on. This is all in keeping with the FDE account; it's just that the given classical consequences are in fact extralogical consequences fueled by the theory-specific investigation - for which, we may assume, the theorist has no good reason to give up methodological principles of 'exhaustion' and 'exclusion' for the theories, especially in the severely tested branches of standard mathematics and its many, many successful applications in science.

Williamson's explanatory-loss objection is in fact partly in response to just such shrieking/shrugging accounts. ${ }^{28}$ He puts the more general worry as follows, where I replace his talk of K3 with the more general example FDE.

is true of recent salient work on truth-theoretic paradoxes $[4,20,33]$ - in parts, very explicitly so. But I hope that the brief replies I give to Williamson's various particular objections are representative of the longstanding responses.

${ }^{27}$ I should note that I agree with much of what Williamson says about the unimportance of having a fully transparent truth predicate in many of our true scientific theories, where a transparent truth predicate is one for which full intersubstitutability is validated by the theory's closure relation $[4,20]$. Of course, if we do have true theories with their own transparent truth predicate - a device whose sole job is to be transparent just so - then the 'choice' between an in-effect classically closed theory and an FDE-closed theory is easy. (The former is trivial; the latter needn't be.) But Williamson's arguments are intended, for all I can see, to be of broader significance against nonclassical accounts of logic, and so I leave talk of various truth predicates to the side.

${ }^{28}$ Williamson cites Field [20], which in one sense does provide an example of subclassical shrieking, but Field's account - like those of Beall [4] and Priest [33] - unfortunately

Australasian Journal of Logic (16:7) 2019, Article no. 2 
There is a more general concern. The retreat to [FDE] invalidates vast swathes of ordinary mathematical reasoning, since mathematicians freely reason in ways that depend on the law of excluded middle. The natural scientists might overcome the restrictions [of FDE] by postulating instances of excluded middle [similarly, shriek rules] as needed. But then their explanations invoke those auxiliary [i.e., extra-logical] assumptions, which reduces their explanatory value; elegant explanations get as much as possible out of as little as possible.... [T] he point is that the auxiliary assumptions are $a d$ hoc for the Kleenean in a way they are not for the classical logician, who derives them all from the simple, elegant, general principles of classical logic.

How does the FDE account of logical consequence reply?

I note first, but only to set it aside, that presumably Williamson's talk of 'reasoning' is supposed to be borne out in the ubiquity of classically closed mathematical theories, where the closure relation mirrors classical consequence. Williamson isn't really talking about the correct theory of reasoning - for example, 'change in view' or acceptance-rejection behaviour - in any serious sense $[23,24]$. After all, if that were the target notion of logical consequence then we would not be talking about consequence as a closure (and, hence, monotonic!) relation; it would be, as the terminology goes, 'non-monotonic logic' through and through. Instead, such talk of the mathematician postulating excluded middle (or its dual) and her 'free reasoning' with such postulates is to be taken as talk of mathematical theories - which, I've agreed, are in effect classically closed.

The crux of the objection rests on the claim that the 'auxiliary assumptions' - that is, the FDE theorist's shriek/shrug rules - reduce the 'explanatory value' of those rules. Why is this? Williamson is clear in his answer:

complicates things with a quest for Curry-suitable conditionals, thereby turning the whole account into something well beyond the elegant FDE account sketched here. Moreover, Williamson invokes Halbach [22], who points out that arithmetical theories in which there is transparent truth and the basement-level closure relation is only K3 are ones that are notably weaker than standard classical-logic-based theories with respect to transfinite induction. This is an issue if one thinks that arithmetic needs to have transparent truth, but I agree with Williamson that such a view of arithmetic - or even other theories in mathematics - is not obviously correct. In any event, the explanatory power on which Williamson's argument rests assumes that our true mathematical theories are classical, and so I assume with him that they don't have a transparent truth predicate - which is why we are setting those issues aside.

Australasian Journal of Logic (16:7) 2019, Article no. 2 
namely, that 'elegant explanations get as much as possible out of as little as possible.' But how is this supposed to count against the shriek and shrug rules? It's true that such rules are implicit in the classical-logic account of the basement-level closure relation, and not implicit in the FDE account. But how does this reduce their explanatory power? Williamson clarifies: 'they're ad hoc for the [FDE theorist] in a way they are not for the [classical-logic theorist], who derives them all from the simple, elegant, general principles of classical logic.' And so, according to Williamson, the problem with shriek/shrug rules is that they're ad hoc and in that respect (alone) not as explanatory as they'd be if they were implicit in all theories.

By way of reply it's worth repeating that the FDE account does, as Williamson says, treat shriek/shrug rules as 'ad hoc' in the sense of being extra-logical and theory-specific. In the same way, the physicist's postulation of spin is ad hoc and extra-logical; the principles governing such a property are specific to the theories involving it. (And so on, for all of our interesting theories.) So, it's not simply the theory-specific ingredients of a theory's extra-logical closure relation that raises the (alleged) explanatory-loss problem. So, what is it?

Williamson points to the fact that the other candidate (namely, the classical-logic candidate) can derive the given shriek/shrug rules in all theories, and so doesn't need them to be explicitly added. (That's just what it is to be logical consequence: the given entailment behaviour for the given connectives is exhibited in all of our true theories. Hence, neither the FDE nor the classical-logic candidate needs to explicitly add De Morgan behaviour.) And that's right. But that alone - the ability to derive from 'simple, elegant general principles' - is not a virtue in itself. After all, once again, Meyer's pure calculus of irrelevance wins hands down on that criterion.

Meyer's pure calculus of irrelevance shouldn't be praised for its ability to elegantly and very simply derive shriek/shrug rules across all theories. Why? Answer: because it clutters the theories with irrelevant untruths. And what we care about are truths - relevant or not. According to the FDE theorist there can be true glutty theories and true (prime) gappy theories. It may well be (in fact, usually is) that there's a methodological stance according to which such possibilities should be ruled out by our theories unless there's special reason to take them seriously. ${ }^{29}$ Of course, if it turns out that at

${ }^{29}$ This may be the case with strange phenomena like the liar, which screams out for a glutty treatment - 'I am not true'! Logic, according to FDE theorists, doesn't force

Australasian Journal of Logic (16:7) 2019, Article no. 2 
the 'end of inquiry' (so to speak) every single true theory of every single phenomenon is classically closed via shriek/shrug rules, then Williamson's point about a simpler account is spot on - no question about it. In that case, there'd be no point in dwelling on the remote 'possibilities' of gluts and gaps - ruled out as theoretically impossible by every single true theory and in that respect a more beautiful account of logic would simply be the classical-logic account. But that's a far cry from where we sit, where the FDE account and classical-logic account are both taken to be live options.

In the end, Williamson's explanatory-loss argument against the FDE account either rules out the account from the start or is ineffective as an objection to it. ${ }^{30}$

\section{References}

[1] Alan Ross Anderson and Nuel D. Belnap. Entailment: The Logic of Relevance and Necessity, volume 1. Princeton University Press, Princeton, 1975 .

[2] Alan Ross Anderson, Nuel D. Belnap, and J. Michael Dunn. Entailment: The Logic of Relevance and Necessity, volume 2. Princeton University Press, Princeton, 1992.

[3] F. G. Asenjo. A calculus of antinomies. Notre Dame Journal of Formal Logic, 7(1):103-105, 1966.

[4] Jc Beall. Spandrels of Truth. Oxford University Press, Oxford, 2009.

[5] Jc Beall. $\mathrm{LP}^{+}, \mathrm{K}^{+}, \mathrm{FDE}^{+}$and their classical collapse. Review of Symbolic Logic, 6(4):742-754, 2013.

[6] Jc Beall. Shrieking against gluts: The solution to the 'just true' problem. Analysis, 73(3):438-445, 2013.

the glut; but the glutty treatment is as natural as the dual gappy one for truth-telling sentences. (But my aim here is not at all to argue this point.)

${ }^{30}$ Acknowledgements: I'm grateful to Ole Hjortland, Graham Priest, Gill Russell and Tim Williamson for very helpful discussion and feedback (not all of which has made it into this final version, mainly due to scheduling constraints). I'm also grateful to Joseph Lurie and Tore Fjetland Øgaard for helpful feedback on a late draft.

Australasian Journal of Logic (16:7) 2019, Article no. 2 
[7] Jc Beall. A simple approach towards recapturing consistent theories in paraconsistent settings. Review of Symbolic Logic, 6(4):755-764, 2013.

[8] Jc Beall. Free of detachment: Logic, rationality, and gluts. Noûs, 49(2):410-423, 2015.

[9] Jc Beall. There is no logical negation: true, false, both, and neither. Australasian Journal of Logic, 14(1), 2017.

[10] Jc Beall. The simple argument for subclassical logic. Philosophical Issues, 28(1):30-54, 2018.

[11] Jc Beall and John P. Burgess. Logic. In Duncan Pritchard, editor, $O x$ ford Bibliographies in Philosophy. Oxford University Press, 2017. DOI: 10.1093/obo/9780195396577-0336.

[12] Jc Beall and Greg Restall. Logical Pluralism. Oxford University Press, Oxford, 2005.

[13] Jc Beall and Bas C. van Fraassen. Possibilities and Paradox: An Introduction to Modal and Many-Valued Logic. Oxford University Press, Oxford, 2003.

[14] N. D. Belnap. Grammatical propaedeutic. In A. R. Anderson, R. C. Barcan-Marcus, and R. M. Martin, editors, The Logical Enterprise, pages 143-165. Yale University Press, New Haven, 1975.

[15] Nuel D. Belnap. How a computer should think. In G. Ryle, editor, Contemporary Aspects of Philosophy. Oriel Press, 1977.

[16] Nuel D. Belnap and J. Michael Dunn. Entailment and the disjunctive syllogism. In F. Fløistad and G. H. von Wright, editors, Philosophy of Language/Philosophical Logic, pages 337-366. Martinus Nijhoff, The Hague, 1973. Reprinted in $[2, \S 80]$.

[17] Kata Bimbó and J. Michael Dunn, editors. Generalized Galois Logics. CSLI Publications, Palo Alto, California, 2008.

[18] J. Michael Dunn. The Algebra of Intensional Logics. PhD thesis, University of Pittsburgh, 1966.

Australasian Journal of Logic (16:7) 2019, Article no. 2 
[19] J. Michael Dunn. Intuitive semantics for first-degree entailments and 'coupled trees'. Philosophical Studies, 29:149-168, 1976.

[20] Hartry Field. Saving Truth from Paradox. Oxford University Press, Oxford, 2008.

[21] Rohan French. Structural reflexivity and the paradoxes of self-reference. Ergo, an Open Access Journal of Philosophy, 3, 2016.

[22] Volker Halbach. Axiomatic Theories of Truth. Cambridge University Press, 2011.

[23] Gilbert Harman. Rationality. In Reasoning, meaning, and mind, pages 9-45. Oxford University Press, Oxford, 1973.

[24] Gilbert Harman. Change in View: Principles of Reasoning. MIT Press, Cambridge, MA, 1986.

[25] Ole Thomassen Hjortland. Anti-exceptionalism about logic. Philosophical Studies, 174(3):631-658, 2017.

[26] I. L. Humberstone and A. J. Lock. Semicomplemented lattices and the finite model property. Zeitschrift fur mathematische Logik und Grundlagen der Mathematik, 32(25-30):431-437, 1986.

[27] S. C. Kleene. Introduction to Metamathematics. North-Holland, 1952.

[28] Edwin Mares. Relevant Logic: A Philosophical Interpretation. Cambridge University Press, Cambridge, 2004.

[29] Edwin Mares and Francesco Paoli. Logical consequence and the paradoxes. Journal of Philosophical Logic, 43(2-3):439-469, 2014.

[30] Robert K. Meyer. Entailment. Journal of Philosophy, 68(21):808-818, 1971.

[31] Francesco Paoli. Substructural Logics: A Primer. Kluwer, Dordrecht, 2002.

[32] Graham Priest. The logic of paradox. Journal of Philosophical Logic, 8:219-241, 1979.

Australasian Journal of Logic (16:7) 2019, Article no. 2 
[33] Graham Priest. In Contradiction. Oxford University Press, Oxford, second edition, 2006. First printed by Martinus Nijhoff in 1987.

[34] Graham Priest. An Introduction to Non-Classical Logic. Cambridge University Press, Cambridge, second edition, 2008. First edition published in 2001.

[35] Graham Priest. Fusion and confusion. Topoi, 34(1):55-61, 2015.

[36] Willard van Orman Quine. Philosophy of Logic. Prentice-Hall, 1970.

[37] Stephen Read. The Philosophy of Logic. Oxford University Press, 1995.

[38] David Ripley. Paradoxes and failures of cut. Australasian Journal of Philosophy, 91(1):139-164, 2013.

[39] Richard Routley. Dialectical logic, semantics and metamathematics. Erkenntnis, 14:301-331, 1979.

[40] Richard Routley and Robert K. Meyer. Dialectical logic, classical logic, and the consistency of the world. Studies in East European Thought, 16(1-2):1-25, 1976.

[41] Gillian Russell. Deviance and vice: strength as a theoretical virtue in the epistemology of logic. Presented at the AAP 2017 in Adelaide AUS., 2017.

[42] Gil Sagi. Logicality and meaning. Review of Symbolic Logic, pages 1-27, 2018. forthcoming.

[43] Lionel Shapiro. Naive structure, contraction and paradox. Topoi, 34(1):75-87, 2015.

[44] Alasdair Urquhart. Distributive lattices with a dual homomorphic operation. Studia Logica, 38(2):201-209, 1979.

[45] Alasdair Urquhart. Distributive lattices with a dual homomorphic operation. ii. Studia Logica, 40(4):391-404, 1981.

[46] Alan Weir. Naive truth and sophisticated logic. In Jc Beall and B. Armour-Garb, editors, Deflationism and Paradox, pages 218-249. Oxford University Press, Oxford, 2005.

Australasian Journal of Logic (16:7) 2019, Article no. 2 
[47] Timothy Williamson. Semantic paradoxes and abductive methodology. In B. Armour-Garb, editor, Reflections on the Liar, pages 325-346. Oxford University Press, Oxford, 2017.

[48] Elia Zardini. Truth without contra(di)ction. Review of Symbolic Logic, 4(4):498-535, 2011.

Australasian Journal of Logic (16:7) 2019, Article no. 2 